\title{
Fluoride Ion Concentration in Brine Solutions, Salt and Pan Soil of Veppalodai, Thoothukudi District, Tamil Nadu, India
}

\author{
S.Ponnusamy ${ }^{1}$, R.Sundarakumar ${ }^{2}$ \\ ${ }^{I}$ (P.G. \& Research Department of Chemistry, Sri Paramakalyani College, Alwarkurichi - 627 412, \\ Tamil Nadu, India) \\ ${ }^{2}$ (Department of Chemistry, Vivekananda Kendra Vidyalaya, Kanyakumari - 629 702, \\ Tamil Nadu, India)
}

\begin{abstract}
The fluoride ion concentration in water samples, salt and pan soil present in the salt pans of Veppalodai, Thoothukudi District were evaluated. The variation of fluoride ion concentration in the samples were supported by electrical conductance studies. The samples were drawn in the summer season for eight days during May 2011. The fluoride content was determined using a standard procedure. The concentration of fluoride ranged between $1.0 \mathrm{ppm}$ and $1.7 \mathrm{ppm}$ was well within the permissible limits. The concentration of fluoride ion increased in the saline water till the start of crystallization and subsequently decreased with an increase in salt formation. During the crystallization process considerable amount of fluoride got settled into the pan soil. The electrical conductivity measurement during this investigation supported the fluoride level in the brine solution.
\end{abstract}

Keywords: Brine, Conductivity, Crystallization, Fluorosis, Saline water, Salt pan.

\section{Introduction}

The fluoride concentration in unpolluted sea waters generally ranges from 1.2 to $1.5 \mathrm{mg} \mathrm{F} / 1$ [1],[2]. Assessments made on a $\mathrm{F}^{-}$exposed group, in Arak with a non $\mathrm{F}^{-}$exposed group suggest that occupational $\mathrm{F}$ has harmful effects on the functions of the central nervous system and can negatively affect both cognitive and psychomotor functions [3]. In a study at Iran, it was found that the mean IQ score of 91.37 of 7-9 year old children in a high $\mathrm{F}$ water $(2.38 \mathrm{mg} \mathrm{F} / \mathrm{l})$ city was lower than the mean IQ score of 97.80 in a low F water (0.41 mg F/l) city [4].

According to safe drinking water quality standards, the concentration of fluoride has to be between 0.6 and $1.0 \mathrm{ppm}$ in potable waters which protects the tooth decay and enhances bone developments [5]. Above $1.5 \mathrm{ppm}$, the severity of fluorosis increases [6]. In recent items the caries increase has been attributed speculatively to changes in fluid intake, including increased consumption of sweet drinks and bottled waters [7]. Excessive intake of fluoride $(\mathrm{F})$ causes fluorosis, which is a progressive degenerative disorder that predominantly affects the skeletal system (Fig.1), teeth and also the structure and function of skeletal muscle[8].

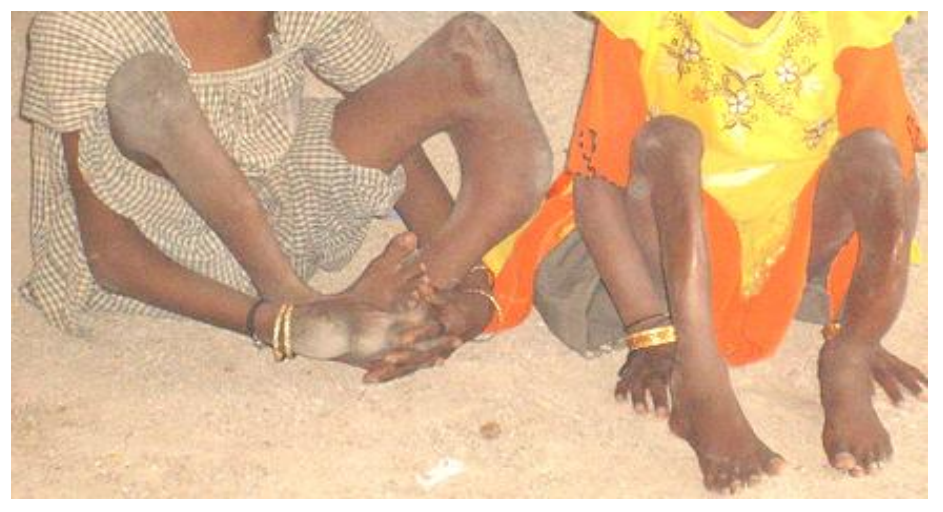

Fig. 1: Bones affected by skeletal fluorosis

Fluorosis originating from $\mathrm{F}$ in drinking water is of great concern in India. In Rajasthan, more than 50 percent of the districts are affected by high $\mathrm{F}$ in ground and drinking water sources [9]. Fluoride affects animals more. Oral administration of $\mathrm{NaF}$ for 30 days causing significant reduction in the body weight of mice has been attributed to lower food consumption resulting in decreased protein synthesis and lower energy metabolism [10]. The activities of superoxide dismutase, catalase and glutathione peroxidase on broilers were significantly lower in high $\mathrm{F}^{-}$groups than those in control group [11]. In another 
study, a group of rats received silymarin followed by $\mathrm{NaF}$, in which silymarin has a potent ameliorative effect on NaF- induced oxidative stress in rat erythrocytes [12].

\section{Materials and Methods}

The study area is located at Veppalodai, Thoothukudi District in the Southern part of India (Fig. 2).

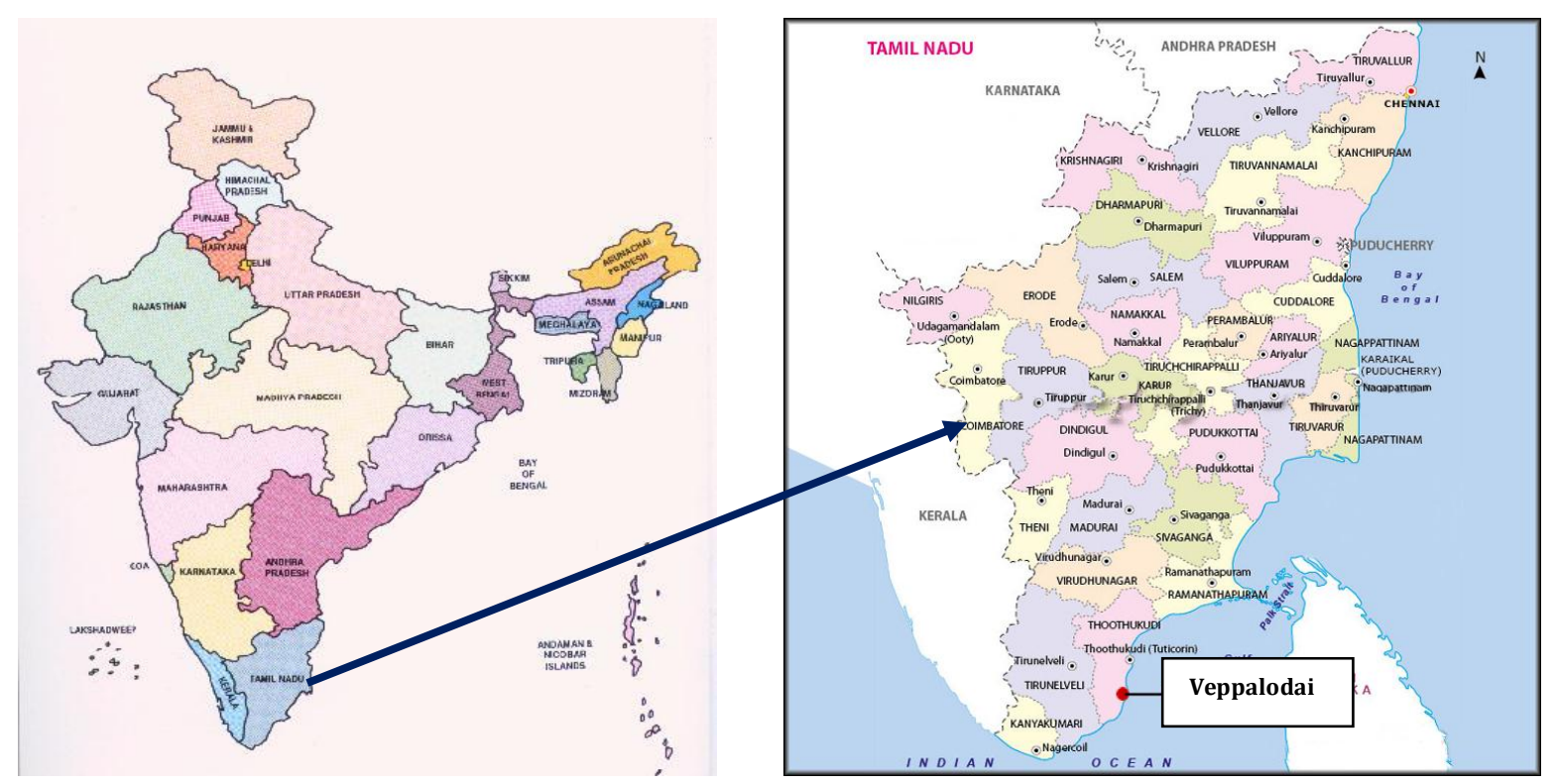

Fig. 2: Location of Veppalodai in South India

Here, the sea water salt pans cover an area of 1011.74 hectares. The brine samples were collected from the salt pan daily for a period of 7 days everyday during the summer season (May, 2011) (Table 1). The sample bottles of 1 litre capacity were first rinsed with de-ionized water and then for two to three times with the brine samples before collecting it for analysis. The concentration of the saline water in a pan gradually increases due to evaporation, and finally it becomes the salt. After the saline water was released from the reservoir pond, the salt got crystallized on the seventh day. The complete crystallized salt and pan soil were collected after its formation. The crystallized, solid salt sample was also collected in a clean polythene container. For analyzing the salt, the salt was converted into a saturated solution by dissolving $390 \mathrm{~g}$ salt in 1 litre of the de-ionised water. Pan soil was collected by inserting a PVC pipe of 2 feet length into the soil. For analyzing the pan soil, $470 \mathrm{~g}$ of the same soil was dissolved in 1 litre of the de-ionized water.

\subsection{Preparation of the reagent}

$70 \mathrm{mg}$ of alizarin red S was dissolved in $50 \mathrm{ml}$ of distilled water. $300 \mathrm{mg}$ of zirconyl chloride octahydrate was dissolved in $50 \mathrm{ml}$ of distilled water. The alizarin red S solution was poured slowly into zirconyl chloride octahydrate solution. After few minutes the solution became clear. This was called as the first solution. To a little amount of distilled water $101 \mathrm{ml}$ of concentrated hydrochloric acid was added and the volume made upto $400 \mathrm{ml}$. To this $33.3 \mathrm{ml}$ of the concentrated sulphuric acid was added. The solution was cooled. The first solution was mixed with the second solution. This mixture was made upto $1000 \mathrm{ml}$ in a standard measuring flask.

\subsection{Analysis of Fluoride}

$100 \mathrm{ml}$ of sample or a portion of sample was taken and diluted to $100 \mathrm{ml}$ in a Nesslers tube. $5 \mathrm{ml}$ of acid - zirconyl alizarin reagent was added and kept in dark. The colour standards were compared after one hour. The volume of standard fluoride which was used for comparing the colours were noted [13], and the fluoride content calculated using the formula,

Fluoride $(\mathrm{ppm})=\frac{\text { Standard fluoride in } \mathrm{ml} \times 50 \times 100}{\text { Sample in } \mathrm{ml}}$

\subsection{Determination of electrical conductance}

Electrical conductance of the water samples were carried out using a conductivity meter (Systronics). The conductivity meter was calibrated using $0.01 \mathrm{~N} \mathrm{KCl}$ solution at $25^{\circ} \mathrm{C}$. The conductivity cell was washed 
free of $\mathrm{KCl}$ solution by distilled water and finally with the respective samples. The electrical conductance of the different saline water samples were measured at $25^{\circ} \mathrm{C}$, and the result was tabulated.

\section{Results}

Fluoride is an important component in brine solutions, salt and pan soil. The fluoride ion concentration and electrical conductivity of the above samples were estimated/measured and are tabulated in Table 1.

Table 1: Analysis of fluoride ion concentration ( $\mathrm{ppm})$ and electrical conductivity $(\mathrm{dS} / \mathrm{m})$ in brine samples,

\begin{tabular}{cccc}
\multicolumn{3}{c}{ Salt and pan soil. } \\
\hline Sample No. & Date of collection & Concentration of Fluoride (ppm) & Electrical conductance (dS/m) \\
\hline S1 & $02-05-2011$ & 1.2 & 149 \\
S2 & $03-05-2011$ & 1.3 & 156 \\
S3 & $04-05-2011$ & 1.4 & 166 \\
S4 & $05-05-2011$ & 1.6 & 173 \\
S5 & $06-05-2011$ & 1.7 & 179 \\
S6 & $07-05-2011$ & 1.4 & 159 \\
S7 & $08-05-2011$ & 1.2 & 146 \\
S8 & $13-05-2011$ & 1.0 & 188 \\
S9 & $13-05-2011$ & 1.0 & 197 \\
\hline
\end{tabular}

S1-S7 indicates brine samples

S8 indicates salt sample

S9 indicates pan soil sample

The amount of fluoride ion present in the saline water samples available in salt pan were analyzed till the crystallization stage and are presented in Fig. 3. As seen in Fig 3, in the initial stage, the concentration of fluoride ion was low and with the progression of sample collection from salt pan daily it increased gradually and attained the maximum value (1.2 ppm to $1.7 \mathrm{ppm}$ ). The higher value of fluoride content gradually declined with the formation of salt during the crystallization process (1.7 ppm to $1.0 \mathrm{ppm})$.

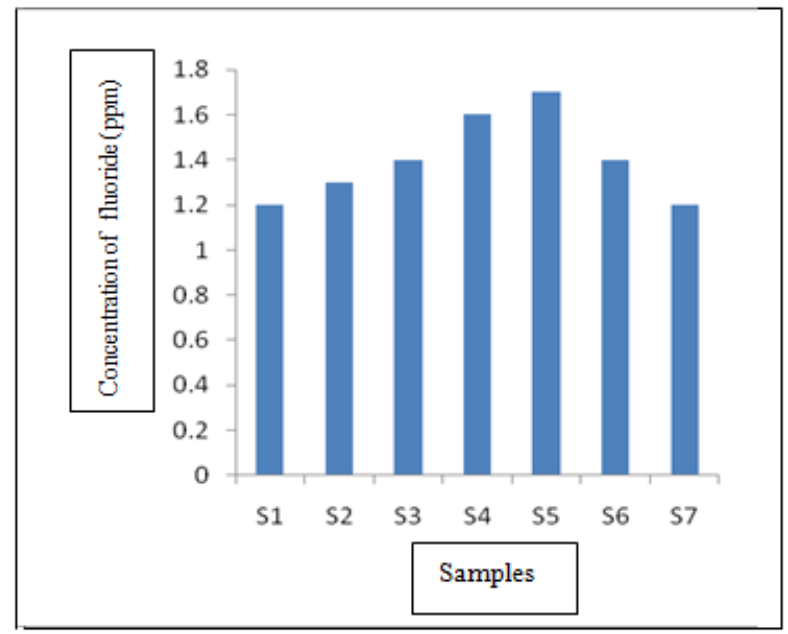

Fig. 3: Fluoride ion concentration in brine samples during crystallization stages.

During the crystallization process considerable amount of fluoride got settled in the pan soil, which was detected to be $1.0 \mathrm{ppm}$. The level of fluoride ion concentration in the various samples collected were also supported aptly by electrical conductivity studies which is portrayed in Fig. 4.

The electrical conductivity of the brine samples measured candidly reflected a gradual increase reaching the highest value of $179 \mathrm{dS} / \mathrm{m}$ which later decreased subsequently ( $146 \mathrm{dS} / \mathrm{m})$. However, on testing the pan soil, the higher E.C.value (197 dS/m) recorded which could be attributed to the existence of other ions that include both cations and anions. 


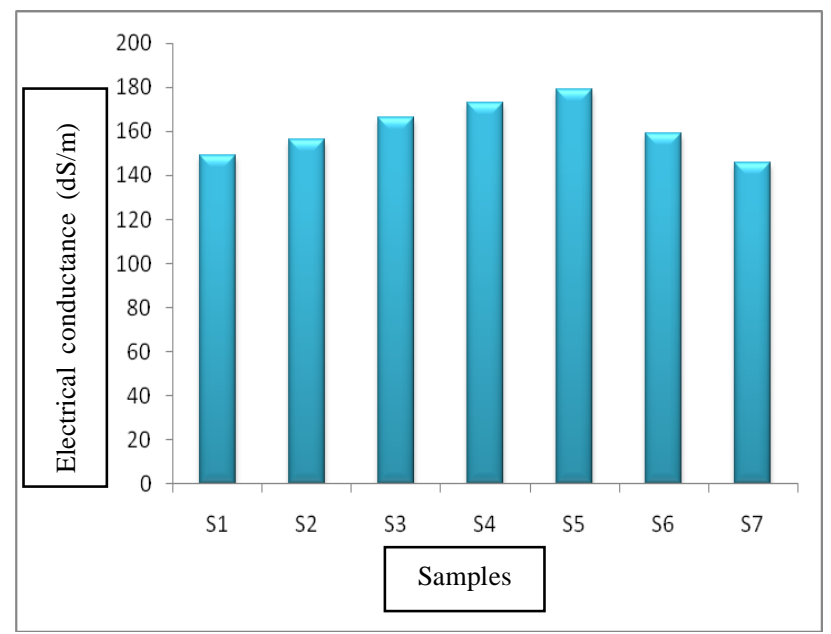

Fig. 4: Electrical conductivity of brine samples during the stages of crystallization

\section{Discussion}

From the results of an analysis on ground water of Arsikere Taluk, Karnataka reported that the fluoride concentration ranged from $1.1 \mathrm{mg} / \mathrm{l}$ to $2.23 \mathrm{mg} / \mathrm{l}$ in post monsoon season [14]. In a study, they have proved the amount of fluoride in ground water was within the permissible limits, which was found to be between $1.22 \mathrm{mg} / \mathrm{l}$ and $1.48 \mathrm{mg} / \mathrm{l}[15]$.

In an analysis they have concentrated about physico-chemical characteristics of ground water and they found out the electrical conductance values in nine of their samples at pre monsoon season which was ranged between 1380 to $2400 \mu \mathrm{S} / \mathrm{cm}$ at $25^{\circ} \mathrm{C}$ [16]. In our samples it was found to be in the range of 1490 to $1970 \mu \mathrm{S} / \mathrm{cm}$.

It is extrapolated from the foregoing works that salt has fluoride ion content under permissible limits (I.S.I. standards). It is also construed that the saline waters of Veppalodai have high level of fluoride initially but on crystallization the salt proceeds to possess only limited content of fluoride (1.0 ppm) making it conducive for human consumption and avoidance fluorosis from health view point.

\section{Acknowledgement}

India.

This study was supported by the officials of Sahayamatha salt terns, Veppalodai, Thoothukudi district,

\section{References}

[1]. J.A. Camargo, Fluoride toxicity to aquatic organisms: A review Chemosphere, 50, 2003, 251 - 264.

[2]. D.K. Datta, L.P. Gupta, and V. Subramanian, Dissolved Fluoride in the lower Ganges - Brahmaputra - Meghna River system in the Bengal Basin Bangladesh, Environ Geol, 39, 2000, 1163- 1168.

[3]. M.Y. Seyedeh, S. Akbar, D.B. Maryam, R.M. Vahid, and A. Omid, Effects of fluoride on psychomotor performance and memory of aluminium potroom workers, Fluoride, 44(3), 2011, 158 - 162.

[4]. H.R. Poureslami, A. Horri, and B. Garrusi, A comparative study of the IQ of children age 7-9 in a high and a low fluoride water city in Iran, Fluoride 44(3), 2011, 163 - 167.

[5]. N. Kundu, M.K. Panigarhi, S. Tripathy, M.A. Powell and B.R. Hart, Geochemical appraisal of fluoride contamination of ground water in the Nayagarh District. Orissa, Environ Geol, 41, 2001, 451- 460.

[6]. WHO, Guidelines for drinking water quality, First Addendum, $3^{\text {rd }}$ Edn. (1) Recommendations, World Health Organization, 2006.

[7]. J. Lee, Brearly - L.J. Messer, Contemporary fluid intake and dental caries in Australian children, Aust Dent J, 56(2), 2011 , $122-131$.

[8]. A. Shashi, J.P. Singh and S.P. Thapar, Protein degradation in skeletal muscle of rabbit during experimental fluorosis, Fluoride, 25, $1992,155-158$.

[9]. R. Gopal, and P.K. Ghosh, Fluoride in drinking water: its effect and removal, Def Sci J, 35(1), 1985, 71- 88

[10]. K.S. Pillai, A.T. Mathai, P.B. Deshmukh, Acute toxicity of fluoride to mice. Fluoride, 20, 1987, 68-70.

[11]. L. Juan, C. Hengmin, Xi Peng, F. Jing, Z. Zhical, W. Hensong, W. Bangyuan, D.Yuanxin, and W. Kangping, High dietary fluorine induction of oxidative damage in the cecal tonsil of broilers, Fluoride, 5(1), 2012, 47 - 52.

[12]. M.N. Seyed, F.N. Seyed, R.L. Monica, S. Antoni, A. Mohammed ali, and H.M. Akbar. Cytoprotective effective of silymarin against sodium fluoride - induced oxidative stress in rat erythrocytes, Fluoride, 45(1), 2012, 27 - 34

[13]. N.C. Aery, Manual of Environmental Analysis,( New Delhi:Thomson press; 2010 (ISBN 978-93-8015-621- 627)).

[14]. Mohammed Naji Taresh ali, Hina Kousar, Adamsab M Patel. Fluoride concentration in groundwater of Arsikere Taluk, Hassan District, Karnataka, India, Nat env \& Poll Tech, 10(3), 2011, 455 - 457.

[15]. S.B. Basavaraddi, Hina Kousar, and E.T. Puttaiah, Fluoride toxicity in groundwater and its chronic effect on human health: A study in Tiptur and its surrounding areas in Karnataka state, India, Nat Env \& Poll Tech, 11(2), 2012, 271 - 276.

[16]. C. Kailash, Sharma, and Mithlesh Agrawal, Assessment of groundwater quality for drinking and irrigation purposes in Banasthali village, District Tonic, Rajasthan, Nat Env \& Poll Tech, 12(4), 2013, 679 - 684. 